\title{
Evaluation of ventilatory threshold and its relation to exercise habits among Japanese
}

\author{
Nobuyuki Miyatake $\cdot$ Motohiko Miyachi $\cdot$ Izumi Tabata $\cdot$ \\ Noriko Sakano • Takeshi Suzue • Tomohiro Hirao • \\ Takeyuki Numata
}

Received: 15 December 2009/Accepted: 6 April 2010/Published online: 28 April 2010

(C) The Japanese Society for Hygiene 2010

\begin{abstract}
Objective The aim of this study was to evaluate aerobic exercise levels, expressed in terms of ventilatory threshold (VT), in a Japanese population and explore the relationship between VT and exercise habits in this population.

Methods This was a cross-sectional study in which data collected from 547 men and 524 women aged 20-69 years and not on medications, were used to assess exercise habits and parameters at VT, namely, oxygen uptake, work rate, and heart rate.

Results Age-related changes in parameters at VT were noted. Of the participants, 205 men (37.5\%) and 142 women $(27.1 \%)$ had exercise habits. Oxygen uptake and work rate at VT in subjects with exercise habits were significantly higher than those without exercise habits after age had been adjusted for in both sexes. Anthropometric parameters were significantly correlated with oxygen uptake at VT, and the highest correlation coefficient rate
\end{abstract}

N. Miyatake $(\bowtie) \cdot$ N. Sakano

Department of Hygiene, Faculty of Medicine,

Kagawa University, Miki-cho, Kita-gun,

Kagawa 761-0793, Japan

e-mail: miyarin@med.kagawa-u.ac.jp

M. Miyachi · I. Tabata

National Institute of Health and Nutrition,

Tokyo 162-8636, Japan

T. Suzue $\cdot$ T. Hirao

Department of Public Health, Faculty of Medicine,

Kagawa University, Miki-cho, Kita-gun, Kagawa 761-0793,

Japan

T. Numata

Okayama Southern Institute of Health, Okayama 700-0952,

Japan was found between oxygen uptake at VT and body fat percentage (men $r=-0.589$, women $r=-0.631$ ).

Conclusion The mean values determined here may provide a useful database for evaluating VT in Japanese adult subjects.

Keywords Exercise habits - Heart rate - Oxygen uptake . Ventilatory threshold $\cdot$ Work rate

\section{Introduction}

Regular physical activity has been shown to increase the level of high-density lipoprotein (HDL) in the blood and to reduce resting blood pressure, abdominal fat, triglyceride and fasting blood sugar levels, and insulin responses to the oral glucose challenge test [1-5]. The National Nutrition Survey in Japan [6] estimated that among the general Japanese population, only $29.1 \%$ of men and $25.6 \%$ of women exercised regularly (exercise habits). This report also recommended that the proportion of the population with exercise habits should be increased to $39 \%$ of men and $35 \%$ of women by 2010 .

In 2006, the Japanese Ministry of Health, Labor and Welfare-sponsored study Exercise and Physical Activity Reference Quantity for Health Promotion 2006 (EPARQ 2006) recommended levels of maximal oxygen uptake as reference quantities for exercise and physical activity reference [7]. Although maximum oxygen uptake is generally considered to be an accurate and reliable parameter, it is not fully applicable to the general population in clinical practice. Ventilatory threshold (VT) is defined as the upper limit of aerobic exercise and is also thought to serve as an accurate and reliable standard for exercise prescription [8]. Since exercise intensity at VT is not harmful to 
Table 1 Clinical profiles of enrolled subjects

\begin{tabular}{lcc}
\hline Clinical and demographic profile & \multicolumn{1}{l}{ Men } & Women \\
\hline Number of subjects & 547 & 524 \\
Age (years) & $41.9 \pm 10.9$ & $44.5 \pm 11.8$ \\
Height $(\mathrm{cm})$ & $170.0 \pm 5.6$ & $156.2 \pm 5.4$ \\
Body weight $(\mathrm{kg})$ & $79.4 \pm 14.3$ & $65.3 \pm 13.1$ \\
Body mass index $\left(\mathrm{kg} / \mathrm{m}^{2}\right)$ & $27.5 \pm 4.6$ & $26.7 \pm 4.9$ \\
Abdominal circumference $(\mathrm{cm})$ & $91.3 \pm 11.5$ & $81.5 \pm 11.5$ \\
Hip circumference $(\mathrm{cm})$ & $98.6 \pm 7.3$ & $96.9 \pm 8.5$ \\
Body fat percentage $(\%)$ & $27.5 \pm 6.5$ & $36.2 \pm 6.8$ \\
\hline
\end{tabular}

Values are given as the mean \pm standard deviation (SD)

cardiovascular function, it can be safely applied to patients with myocardial infarction as exercise prescription [9]. However, the link between VT and exercise habits in a large sample of Japanese has not yet been investigated.

In the study reported here, we evaluated VT in Japanese subjects and compared the results between subjects who had exercise habits and those who did not.

\section{Subjects and methods}

\section{Subjects}

This was a cross-sectional study in which data on 547 men (mean age $41.9 \pm 10.9$ years) and 524 women (mean age $44.5 \pm 11.8$ years) were evaluated. The age range of the subject cohort was $20-69$ years. The participants met the following criteria (Table 1): (1) they had wanted to change their lifestyle in terms of diet and exercise habits and had undergone an annual health check-up at Okayama Southern Institute of Health; (2) their VT and exercise habits had been evaluated as part of their annual health check-up; (3) they were not taking any medications. All subjects provided written informed consent for the use of their data in the study.

Ethical approval for the study was obtained from the Ethical Committee of Okayama Health Foundation.

\section{Anthropometric measurements}

The anthropometric measurements included height, body weight, abdominal circumference, hip circumference, and body fat percentage. Height and body weight was measured by AD-6225 (A\&D Co, Tokyo, Japan). The body mass index (BMI) was calculated using the formula weight/ (height $)^{2}\left(\mathrm{~kg} / \mathrm{m}^{2}\right)$. Abdominal circumference was measured at the umbilical level, and the hip circumference was measured at the widest circumferences over the trochanter in standing subjects after normal expiration [10]. Body fat percentage was measured by an air displacement plethysmograph called the BOD POD Body Composition System (Life Measurement Instruments, Concord, CA) [11, 12]. The coefficient variation $(\mathrm{CV}, \%)$ for same-day tests was 2.48 , that for three separate-day tests was 2.27 , and that for independent operators was 4.53 . There was a clear correlation between the results from BOD POD and those from dual-energy X-ray absorptiometry (DEXA) $(r=0.910$, $P<0.01)$ [11].

\section{Exercise testing}

The subjects were asked to perform a graded ergometer exercise procedure [13]. A resting electrocardiogram (ECG) was recorded and the blood pressure was measured in each subject $2 \mathrm{~h}$ after breakfast. Each participant then began a graded exercise program after 3 min of pedaling on an unloaded bicycle ergometer (Excalibur V2.0; Lode BV, Groningen, the Netherlands). The profile of incremental workloads was automatically defined by the methods of Jones [13], in which the workloads reach the predicted $\mathrm{VO}_{2 \max }$ in $10 \mathrm{~min}$. A pedaling cycle rate of $60 \mathrm{rpm}$ was maintained. Loading was terminated when the appearance of symptoms forced the subject to stop. During the test, the ECG was monitored continuously together with the recording of the heart rate (HR). Expired gas was collected, and the rates of oxygen consumption $\left(\mathrm{VO}_{2}\right)$ and carbon dioxide production $\left(\mathrm{VCO}_{2}\right)$ were measured breathby-breath using a cardiopulmonary gas exchange system (Oxycon Alpha; Mijnhardt, the Netherlands). The VT was determined using the standard of Wasserman et al. [8], Davis et al. [14], and the V-slope method of Beaver [15] from $\mathrm{VO}_{2}, \mathrm{VCO}_{2}$, and minute ventilation (VE). Validation and reproducibility of the VT were proven in a previous study [14]. At VT, $\mathrm{VO}_{2}(\mathrm{ml} / \mathrm{kg} / \mathrm{min})$, work rate (W), and HR (beats/min) were measured and recorded.

\section{Exercise habits}

Data on exercise habits were obtained at interviews conducted by well-trained staff using the structured method of the National Nutrition Survey in Japan. The subjects were asked if they currently exercise (over $30 \mathrm{~min}$ per session, two times per week for a duration of 3 months). When the answer was "yes", they were classified as subjects with exercise habits (exercised regularly). When the answer was "no", they were classified as subjects without exercise habits.

Statistical analysis

Data were expressed as the mean \pm standard deviation (SD). Comparisons between two groups were performed 
Table 2 Parameters at ventilatory threshold (VT) according to age group

\begin{tabular}{|c|c|c|c|c|c|c|c|c|}
\hline \multirow[t]{2}{*}{ Age } & \multicolumn{4}{|l|}{ Men } & \multicolumn{4}{|l|}{ Women } \\
\hline & $\begin{array}{l}\text { Number } \\
\text { of subjects }\end{array}$ & Mean \pm SD & Minimum & Maximum & $\begin{array}{l}\text { Number } \\
\text { of subjects }\end{array}$ & Mean \pm SD & Minimum & Maximum \\
\hline \multicolumn{9}{|c|}{ Oxygen uptake at VT (ml/kg/min) } \\
\hline $20-29$ & 85 & $15.8 \pm 4.7$ & 9.3 & 33.9 & 79 & $13.4 \pm 3.2$ & 9.3 & 23.5 \\
\hline $30-39$ & 149 & $15.0 \pm 4.1$ & 8.7 & 31.2 & 96 & $13.7 \pm 3.6^{\mathrm{a}}$ & 9.2 & 27.3 \\
\hline $40-49$ & 167 & $14.9 \pm 3.4$ & 8.7 & 29.8 & 155 & $12.3 \pm 2.0^{\mathrm{a}, \mathrm{b}}$ & 8.3 & 20.2 \\
\hline $50-59$ & 117 & $14.0 \pm 2.5^{\mathrm{a}}$ & 10.1 & 24.6 & 138 & $11.9 \pm 1.9^{\mathrm{a}, \mathrm{b}}$ & 7.8 & 18.9 \\
\hline $60-69$ & 29 & $12.9 \pm 1.7^{\mathrm{a}}$ & 10.5 & 19.3 & 56 & $11.8 \pm 1.8^{\mathrm{a}}$ & 8.3 & 16.4 \\
\hline Total & 547 & $14.8 \pm 3.7$ & 8.7 & 33.9 & 524 & $12.6 \pm 2.6$ & 7.8 & 27.3 \\
\hline \multicolumn{9}{|c|}{ Work rate at VT (W) } \\
\hline $20-29$ & 85 & $92.9 \pm 26.2$ & 50.0 & 190.0 & 79 & $60.7 \pm 16.5$ & 30.0 & 125.0 \\
\hline $30-39$ & 149 & $86.4 \pm 22.0$ & 35.0 & 175.0 & 96 & $60.3 \pm 17.4$ & 30.0 & 135.0 \\
\hline $40-49$ & 167 & $80.4 \pm 22.3^{\mathrm{a}}$ & 20.0 & 175.0 & 155 & $50.6 \pm 11.5^{\mathrm{a}, \mathrm{b}}$ & 20.0 & 90.0 \\
\hline $50-59$ & 117 & $73.2 \pm 17.6^{\mathrm{a}, \mathrm{b}}$ & 35.0 & 120.0 & 138 & $47.3 \pm 11.3^{\mathrm{a}, \mathrm{b}}$ & 15.0 & 102.0 \\
\hline $60-69$ & 29 & $60.1 \pm 12.9^{\mathrm{a}, \mathrm{b}, \mathrm{c}}$ & 35.0 & 85.0 & 56 & $39.9 \pm 8.8^{\mathrm{a}, \mathrm{b}, \mathrm{c}, \mathrm{d}}$ & 20.0 & 60.0 \\
\hline Total & 547 & $81.4 \pm 23.0$ & 20.0 & 190.0 & 524 & $51.9 \pm 14.9$ & 15.0 & 135.0 \\
\hline \multicolumn{9}{|c|}{ Heart rate at VT (beat/min) } \\
\hline $20-29$ & 85 & $115.1 \pm 11.7$ & 85.0 & 149.0 & 79 & $114.1 \pm 11.4$ & 86.0 & 137.0 \\
\hline $30-39$ & 149 & $107.8 \pm 10.1^{\mathrm{a}}$ & 83.0 & 139.0 & 96 & $110.0 \pm 11.7$ & 85.0 & 141.0 \\
\hline $40-49$ & 167 & $105.6 \pm 11.4^{\mathrm{a}}$ & 71.0 & 145.0 & 155 & $107.6 \pm 10.4^{\mathrm{a}}$ & 75.0 & 137.0 \\
\hline $50-59$ & 117 & $99.7 \pm 10.6^{\mathrm{a}, \mathrm{b}, \mathrm{c}}$ & 70.0 & 130.0 & 138 & $103.4 \pm 11.2^{\mathrm{a}, \mathrm{b}, \mathrm{c}}$ & 80.0 & 147.0 \\
\hline $60-69$ & 29 & $98.3 \pm 10.2^{\mathrm{a}, \mathrm{b}, \mathrm{c}}$ & 83.0 & 117.0 & 56 & $98.9 \pm 12.5^{\mathrm{a}, \mathrm{b}, \mathrm{c}}$ & 71.0 & 130.0 \\
\hline Total & 547 & $106.0 \pm 12.0$ & 70.0 & 149.0 & 524 & $107.0 \pm 12.1$ & 71.0 & 147.0 \\
\hline
\end{tabular}

${ }^{\mathrm{a}} P<0.05$ vs. age $20-29$ years

b $P<0.05$ vs. age $30-39$ years

${ }^{c} P<0.05$ vs. age $40-49$ years

${ }^{\mathrm{d}} P<0.05$ vs. age $50-59$ years

using the unpaired $t$ test and covariance analysis; comparisons among more than three groups were performed by the analysis of variance (ANOVA) and Scheffe's $F$ test. $P<0.05$ was considered to indicate statistical significance. The Pearson's correlation coefficients were calculated to test for the significance of the linear relationship among continuous variables.

\section{Results}

Parameters at VT according to age group are summarized in Table 2. In men, oxygen uptake and work rate at VT decreased significantly with increasing age in subjects $>50$ years and $>40$ years, respectively, and HR at VT significantly decreased with increasing age in subjects $>30$ years. In women, oxygen uptake at VT decreased significantly with increasing age in subjects $>40$ years, as did both work rate and HR.
Table 3 Prevalence of subjects with exercise habits

\begin{tabular}{lcc}
\hline Age & $\begin{array}{l}\text { Number of subjects } \\
\text { with (+) exercise } \\
\text { habits }(\%)\end{array}$ & $\begin{array}{l}\text { Number of subjects } \\
\text { without }(-) \text { exercise } \\
\text { habits }(\%)\end{array}$ \\
\hline Men & & \\
$20-29$ & $29(34.1)$ & $56(65.9)$ \\
$30-39$ & $46(30.9)$ & $103(69.1)$ \\
$40-49$ & $72(43.1)$ & $95(56.9)$ \\
$50-59$ & $41(35.0)$ & $76(65.0)$ \\
$60-69$ & $17(58.6)$ & $12(41.4)$ \\
Total & $205(37.5)$ & $342(62.5)$ \\
Women & & $64(81.0)$ \\
$20-29$ & $15(19.0)$ & $75(78.1)$ \\
$30-39$ & $21(21.9)$ & $126(81.3)$ \\
$40-49$ & $29(18.7)$ & $92(66.7)$ \\
$50-59$ & $46(33.3)$ & $25(44.6)$ \\
$60-69$ & $31(55.4)$ & $382(72.9)$ \\
Total & $142(27.1)$ &
\end{tabular}


Table 4 Comparison of VT between Japanese subjects with exercise habits and those without

\begin{tabular}{lcccc}
\hline Parameters & $\begin{array}{l}\text { Exercise } \\
\text { habit }(+)\end{array}$ & $\begin{array}{l}\text { Exercise } \\
\text { habit }(-)\end{array}$ & $P$ & $\begin{array}{l}P \text { after adjusting } \\
\text { for age }\end{array}$ \\
\hline Men & & & & \\
$\quad$ Age & $43.2 \pm 11.1$ & $41.1 \pm 10.7$ & $0.0317^{*}$ & \\
$\quad$ Oxygen uptake at VT (ml/kg/min) & $16.2 \pm 4.7$ & $13.9 \pm 2.5$ & $<0.0001^{*}$ & $<0.0001^{*}$ \\
Work rate at VT $(\mathrm{W})$ & $87.5 \pm 28.0$ & $77.7 \pm 18.4$ & $<0.0001^{*}$ & $<0.0001^{*}$ \\
Heart rate at VT $(\mathrm{beat} / \mathrm{min})$ & $104.9 \pm 12.9$ & $106.7 \pm 11.3$ & 0.0793 & 0.3660 \\
Women & & & & \\
Age & $48.5 \pm 12.4$ & $43.0 \pm 11.2$ & $<0.0001^{*}$ & \\
Oxygen uptake at VT (m1/kg/min) & $13.5 \pm 3.6$ & $12.2 \pm 2.1$ & $<0.0001^{*}$ & $<0.0001^{*}$ \\
Work rate at VT $(\mathrm{W})$ & $55.9 \pm 19.4$ & $50.4 \pm 12.5$ & $0.0002^{*}$ & $<0.0001^{*}$ \\
Heart rate at VT (beat/min) & $104.9 \pm 12.3$ & $107.7 \pm 11.9$ & $0.0177^{*}$ & 0.2195 \\
\hline
\end{tabular}

Values are given as the mean $\pm \mathrm{SD}$

* Significant at $P<0.05$ uptake at VT and body fat percentage (men $r=-0.589$, women $r=-0.631$ ). summarized in Table 3. A total of 205 men $(37.5 \%)$ and 142 women $(27.1 \%)$ reported exercising regularly, and the prevalence of subjects with exercise habits gradually increased with age, being highest for subjects in their 60s in both sexes (men 58.6\%, women $55.4 \%$ ).

We compared the VT in our subjects according to Japanese subjects with and without regular exercise habits (Table 4). The HR at VT in subjects with exercise habits was similar to that in subjects without exercise habits in men. Oxygen uptake and work rate at VT in both sexes were significantly higher for subjects with exercise habits than for those without exercise habits. However, the age of subjects with exercise habits was significantly higher than that of subjects without exercise habits. Therefore, we used age as a covariate and in a covariance analysis we compared VT between our Japanese subjects with exercise habits and those without. After adjusting for age in both sexes, we found that oxygen uptake and work rate at VT were significantly higher in subjects with exercise habits than in those without.

We also compared VT between subjects with and without exercise habits according to age group (Table 5). Oxygen uptake at VT in men $<50$ years and in their $60 \mathrm{~s}$ and work rate at $\mathrm{VT}$ in men $<50$ years were significantly higher in subjects with exercise habits than in those without; in comparison, HR at VT in men in their 50s was significantly lower in subjects with exercise habits than in those without. In comparison, oxygen uptake at VT in women $<50$ years and work rate at VT in women $<60$ years were significantly higher in subjects with exercise habits than in those without.

Finally, we evaluated the relationship between oxygen uptake at VT and age and anthropometric parameters (Table 6; Fig. 1). Oxygen uptake at VT was negatively correlated with age and anthropometric parameters. The highest correlation coefficient was found between oxygen

\section{Discussion}

In this study, we explored VT and its relation to exercise habits in a Japanese population according to age groups. This information should serve as a useful database for evaluating VT in Japanese subjects.

The prevalence of subjects with exercise habits in Japan was reported to be $29.1 \%$ of men and $25.6 \%$ of women by the National Nutrition Survey in Japan. The definition of duration in our study, namely, 3 months, was shorter than that in the survey definition, and we did not enroll subjects who took medications. The subjects participating in our study undertook annual health check-ups and exercise tests and, consequently, they may be more careful of their own health than the subjects in the National Nutrition Survey. Therefore, our results according to the analysis of subjects without medications were higher than those in the Survey.

There are only a few reports on maximal oxygen uptake as a direct measure in healthy Japanese individuals. Ohta et al. [16] reported that maximal oxygen uptake significantly decreased with age in 832 apparently healthy subjects and could be expressed as a single regression formula: $y$ (maximal oxygen uptake in $\mathrm{ml} / \mathrm{kg} / \mathrm{min})=46.6-0.36 \times$ age $(r=-0.447)$ in men and $y=35.3-0.23 \times$ age $(r=$ $-0.407)$ in women. We also found an age-related decrease in maximal oxygen uptake among Japanese not taking medications, as reported earlier [17]. It has also been reported that there is significant loss in oxygen uptake at VT with aging [18, 19]. Sanada et al. [18] reported a negative correlation between oxygen uptake at VT and age in 1463 Japanese. Miura reported that oxygen uptake at VT was significantly correlated with age (men $r=-0.626$, women $r=-0.578$ ) in 610 Japanese [19]. In this latter study, an age-related 
Table 5 Comparison of VT between Japanese with and without exercise habits classified by age group

\begin{tabular}{|c|c|c|c|c|c|c|}
\hline \multirow[t]{2}{*}{ Age } & \multicolumn{3}{|l|}{ Men } & \multicolumn{3}{|l|}{ Women } \\
\hline & Exercise habits $(+)$ & Exercise habits $(-)$ & $P$ & Exercise habits $(+)$ & Exercise habits $(-)$ & $P$ \\
\hline \multicolumn{7}{|c|}{ Oxygen uptake at VT $(\mathrm{ml} / \mathrm{kg} / \mathrm{min})$} \\
\hline $20-29$ & $18.0 \pm 5.7$ & $14.7 \pm 3.7$ & $0.0020^{*}$ & $15.4 \pm 4.3$ & $12.9 \pm 2.7$ & $0.0049 *$ \\
\hline $30-39$ & $17.9 \pm 5.3$ & $13.7 \pm 2.4$ & $<0.0001^{*}$ & $17.4 \pm 5.4$ & $12.7 \pm 1.9$ & $<0.0001 *$ \\
\hline $40-49$ & $16.0 \pm 4.4$ & $14.0 \pm 2.0$ & $0.0001 *$ & $13.0 \pm 2.4$ & $12.1 \pm 1.9$ & $0.0403 *$ \\
\hline $50-59$ & $14.6 \pm 3.1$ & $13.7 \pm 2.1$ & 0.0759 & $12.4 \pm 2.1$ & $11.7 \pm 1.8$ & 0.0548 \\
\hline $60-69$ & $13.5 \pm 1.9$ & $12.0 \pm 1.0$ & $0.0171 *$ & $12.2 \pm 1.9$ & $11.3 \pm 1.5$ & 0.0520 \\
\hline \multicolumn{7}{|c|}{ Work rate at VT $(\mathrm{W})$} \\
\hline $20-29$ & $104.0 \pm 33.7$ & $87.1 \pm 19.2$ & $0.0041 *$ & $74.0 \pm 24.2$ & $57.6 \pm 12.4$ & $0.0003 *$ \\
\hline $30-39$ & $99.5 \pm 25.8$ & $80.5 \pm 17.2$ & $<0.0001^{*}$ & $74.2 \pm 26.5$ & $56.4 \pm 11.2$ & $<0.0001 *$ \\
\hline $40-49$ & $86.4 \pm 26.1$ & $75.9 \pm 17.8$ & $0.0024 *$ & $57.4 \pm 12.4$ & $49.0 \pm 10.8$ & $0.0003 *$ \\
\hline $50-59$ & $75.4 \pm 18.5$ & $71.9 \pm 17.0$ & 0.3074 & $50.5 \pm 10.0$ & $45.7 \pm 11.6$ & $0.0177 *$ \\
\hline $60-69$ & $60.9 \pm 15.3$ & $59.0 \pm 9.0$ & 0.7067 & $41.4 \pm 8.8$ & $38.0 \pm 8.7$ & 0.1522 \\
\hline \multicolumn{7}{|c|}{ Heart rate at VT (beat/min) } \\
\hline $20-29$ & $113.8 \pm 12.8$ & $115.7 \pm 11.1$ & 0.4803 & $111.7 \pm 12.5$ & $114.7 \pm 11.2$ & 0.3743 \\
\hline $30-39$ & $108.3 \pm 10.0$ & $107.7 \pm 10.2$ & 0.7349 & $110.4 \pm 14.4$ & $109.9 \pm 11.0$ & 0.8711 \\
\hline $40-49$ & $105.5 \pm 13.1$ & $105.6 \pm 10$ & 0.9429 & $105.3 \pm 10.4$ & $108.1 \pm 10.4$ & 0.2048 \\
\hline $50-59$ & $96.7 \pm 10.7$ & $101.3 \pm 10.3$ & $0.0262 *$ & $103.2 \pm 10.6$ & $103.5 \pm 11.5$ & 0.8475 \\
\hline $60-69$ & $97.3 \pm 10.0$ & $99.8 \pm 10.8$ & 0.5338 & $100.2 \pm 12.5$ & $97.3 \pm 12.6$ & 0.3916 \\
\hline
\end{tabular}

Values are given as the mean $\pm \mathrm{SD}$

* Significant at $P<0.05$

Table 6 Simple correlation analysis between oxygen uptake at VT threshold and age and anthropometric parameters

\begin{tabular}{|c|c|c|c|c|}
\hline \multirow{2}{*}{$\begin{array}{l}\text { Age/anthropometric } \\
\text { parameters }\end{array}$} & \multicolumn{2}{|l|}{ Men } & \multicolumn{2}{|l|}{ Women } \\
\hline & $r$ & $P$ & $r$ & $P$ \\
\hline Age (years) & -0.193 & $<0.0001$ & -0.254 & $<0.0001$ \\
\hline Body weight $(\mathrm{kg})$ & -0.415 & $<0.0001$ & -0.440 & $<0.0001$ \\
\hline Body mass index $\left(\mathrm{kg} / \mathrm{m}^{2}\right)$ & -0.437 & $<0.0001$ & -0.466 & $<0.0001$ \\
\hline $\begin{array}{l}\text { Abdominal circumference } \\
(\mathrm{cm})\end{array}$ & -0.541 & $<0.0001$ & -0.521 & $<0.0001$ \\
\hline Hip circumference $(\mathrm{cm})$ & -0.393 & $<0.0001$ & -0.410 & $<0.0001$ \\
\hline Body fat percentage $(\%)$ & -0.589 & $<0.0001$ & -0.631 & $<0.0001$ \\
\hline
\end{tabular}
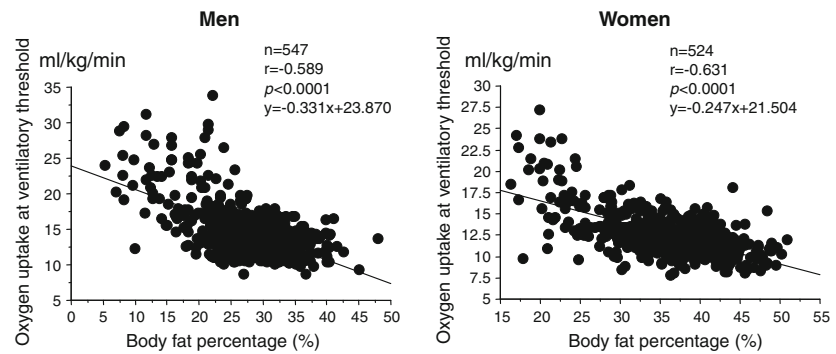

Fig. 1 Simple correlation analysis between oxygen uptake at VT and body fat percentage in Japanese decrease of VT was noted among Japanese not taking medications. These mean values hold promise as a quite useful database for evaluating VT in Japanese subjects.

Although oxygen uptake and work rate at VT in subjects with exercise habits was significantly higher than those in subjects without exercise habits after age had been adjusted for, we found no significant differences in oxygen uptake at VT for men in their 50s and women $>50$ years nor in work rate at VT in men $>50$ years and women $>60$ years. According to the National Nutrition Survey in Japan, the prevalence of subjects with exercise habits increases with age, while daily step counts decrease with age [20]. Lower exercise intensity and shorter exercise time in elderly adults as well as the small sample size may make it difficult to infer causality between VT and exercise habits in these groups. Based on their analysis of 709 apparently healthy Japanese men and women, Zhang et al. [21] also showed that, relative to the subgroup with the fewest walk steps, a significantly greater peak oxygen uptake occurred only in females aged 30-49 years. However, Sandvik et al. [22] reported that physical fitness was a graded, independent, long-term predictor of mortality from cardiovascular causes in healthy, middle-aged men. Miura [19] have that oxygen uptake at VT was positively correlated with mean number of steps per day. Jones et al. [13] also reported that 
the extent of leisure time activity exerted a positive influence on $\mathrm{VO}_{2}$. Therefore, it seems reasonable to suggest that mortality among a proportion of the Japanese population may possibly be decreased simply by improving oxygen uptake at VT through the promotion of exercise habits.

A relationship between maximal oxygen uptake and body composition has been reported in the literature. Significant relationships between maximal oxygen uptake and body fat percentage were noted in Japanese junior high school boys and girls [23], African-American adolescents [24] and Danish women [25]. In an earlier study, we also found that maximal oxygen uptake was significantly correlated with body fat percentage as measured by dual X-ray absorptiometry [17]. Although we could not infer causality between oxygen uptake at VT and body fat percentage and we could not directly measure visceral fat area by computed tomography in this study, an excess of body fat, which is expressed as body fat percentage (\%), may be an excess weight and play a critical role in determining oxygen uptake at VT. This result suggests that body fat percentage may be a good predictor for estimating oxygen uptake at VT in Japanese.

In conclusion, the mean values reported here may provide a useful database for evaluating VT in Japanese adult subjects. Although oxygen uptake and work rate at VT in subjects with exercise habits were significantly higher than those in subjects without exercise habits after age had been adjusted for, there were no significant differences in oxygen uptake at VT in men in their 50s and in women $>50$ years. In addition, this study was a cross-sectional — not a longitudinal-study. Further prospective investigation studies to evaluate the relationship between VT and exercise habits should be carried out in the general Japanese population.

Acknowledgments This research was supported in part by Research Grants from the Ministry of Health, Labor, and Welfare, Japan.

\section{References}

1. Miyatake N, Takahashi K, Wada J, Nishikawa H, Morishita A, Suzuki H, et al. Daily exercise lowers blood pressure and reduces visceral fat in overweight Japanese men. Diabetes Res Clin Pract. 2003;62:149-57.

2. Barnard RJ, Ugianskis EJ, Martin DA, Inkeles SB. Role of diet and exercise in the management of hyperinsulinemia and associated atherosclerotic risk factors. Am J Cardiol. 1992;69:440-4.

3. Miyatake N, Nishikawa H, Morishita A, Kunitomi M, Wada J, Suzuki $\mathrm{H}$, et al. Daily walking reduces visceral adipose tissue areas and improves insulin resistance in Japanese obese subjects. Diabetes Res Clin Pract. 2002;58:101-7.

4. Yamanouchi K, Shinozaki T, Chikada K, Nishikawa T, Ito K, Shimizu S, et al. Daily walking combined with diet therapy is a useful means for obese NIDDM patients not only to reduce body weight but also to improve insulin sensitivity. Diabetes Care. 1995;18:775-8.

5. Ohida Y, Yamanouchi K, Hayamizu S, Sato Y. Long-term mild jogging increases insulin action despite no influence on body mass index or $\mathrm{VO}_{2}$ max. J Appl Physiol. 1989;66:2206-10.

6. National Nutrition Survey in Japan. Available at: http://www. mhlw.go.jp/houdou/2008/12/dl/h1225-5i.pdf. Accessed 5 April 2010.

7. Exercise and Physical Activity Reference Quantity for Health Promotion 2006 (EPARQ2006). Available at: http://www.nih.go. jp/eiken/programs/pdf/epar2006.pdf. Accessed 5 April 2010.

8. Wasserman K, Whipp BJ, Koyl SN, Beaver WL. Anaerobic threshold and respiratory gas exchange during exercise. J Appl Physiol. 1973;35:236-43.

9. Weber KT, Janicki JS. Cardiopulmonary exercise testing for evaluation of chronic cardiac failure. Am $\mathrm{J}$ Cardiol. 1985;55:22-31.

10. Definition and the diagnostic standard for metabolic syndromeCommittee to Evaluate Diagnostic Standards for Metabolic Syndrome (in Japanese). Nippon Naika Gakkai Zasshi. 2005;94: 794-809.

11. Miyatake N, Nonaka K, Fujii M. A new air displacement plethysmograph for the determination of Japanese body composition. Diabetes Obes Metab. 1999;1:347-51.

12. Mccrory MA, Gomez TD, Bernauer EM, Mole PA. Evaluation of a new air displacement plethysmograph for measuring human body composition. Med Sci Sports Exerc. 1995;27:1686-91.

13. Jones NL, Makrides L, Hitchcock C, Chypchar T, McCartney N. Normal standards for an incremental progressive cycle ergometer test. Am Rev Respir Dis. 1985;131:700-8.

14. Davis JA, Frank MH, Whipp BJ, Wasserman K. Anaerobic threshold alterations caused by endurance training in middle-aged men. J Appl Physiol. 1979;46:1039-46.

15. Beaver WL, Wasserman K, Whipp BJ. A new method for detecting anaerobic threshold by gas exchange. J Appl Physiol. 1986;60:2020-7.

16. Ohta T, Zhang J, Ishikawa K, Tabata I, Yoshitake Y, Miyashita M. Peak oxygen uptake, ventilatory threshold and leg extension power in apparently healthy Japanese (in Japanese). Nippon Koshu Eisei Zasshi. 1999;46:289-97.

17. Miyatake N, Miyachi M, Tabata I, Numata T. Body fat percentage measured by dual energy X-ray absorptiometry is associated with maximal oxygen uptake in Japanese. Anti Aging Med. 2009;6:41-5.

18. Sanada K, Kuchiki T, Miyachi M, McGrath K, Higuchi M, Ebashi H. Effect of age on ventilatory threshold and peak oxygen uptake normalized for regional skeletal mass in Japanese men and women aged 20-80 years. Eur J Appl Physiol. 2006;99: 475-83.

19. Miura K. Ventilatory threshold in Japanese-as the basis for exercise prescription for health promotion (in Japanese). Nippon Koshu Eisei Zasshi. 1996;43:220-30.

20. National Nutrition Survey in Japan. Available at: http://www. mhlw.go.jp/houdou/2008/04/dl/h0430-2g.pdf. Accessed 5 April 2010.

21. Zhang JG, Ohta T, Ishikawa-Takata K, Tabata I, Miyashita M. Effects of daily activity by pedometer on peak oxygen consumption $\left(\mathrm{VO}_{2}\right.$ peak), ventilator threshold and leg extension power in 30- to 69-year-old Japanese without exercise habit. Eur J Appl Physiol. 2003;90:109-13.

22. Sandvik L, Erikssen J, Thaulow E, Erikssen G, Mundal R, Rodahl K. Physical fitness as a predictor of mortality among healthy, middle-aged Norwegian men. N Engl J Med. 1993;25:533-7.

23. Watanabe K, Nakadomo F, Maeda K. Relationship between body composition and cardiorespiratory fitness in Japanese junior high school boys and girls. Ann Physiol Anthropol. 1994;13:167-74. 
24. Drinkard B, McDuffie J, McCann S, Uwaifo GI, Nicholson J, Yanovski JA. Relationship between walk/run performance and cardiorespiratory fitness in adolescents who are overweight. Phys Ther. 2001;81:1889-96.
25. Andersen LB, Haraldsdottir J. Maximal oxygen uptake, maximal voluntary isometric contraction and physical activity in young Danish adults. Eur J Appl Physiol Occup Physiol. 1993;67: 315-20. 